\title{
OBTENÇÃO DE MICROESTRUTURA MULTICONSTITUÍDA EM UM AÇO BAIXA-LIGA A PARTIR DE TRATAMENTO ISOTÉRMICO DE TRANSFORMAÇÃO BAINÍTICA*
}

Marlos Henrique Alves Gomes ${ }^{1}$ Almir Gonçalves Vieira ${ }^{2}$ Ivete Peixoto Pinheiro ${ }^{3}$

\section{Resumo}

Aços resistentes ao desgaste são amplamente aplicados em partes estruturais que exigem propriedades como resistência mecânica, tenacidade e resistência ao desgaste abrasivo. 0 presente trabalho foi realizado devido à necessidade de desenvolvimento de materiais necessários para minimizar os efeitos causados pelo desgaste abrasivo. Os objetivos são: obter microestrutura multiconstituída (ferrita, bainita, martensita e austenita retida) por meio de tratamentos térmicos; e compará-la a microestrutura martensítica revenida. $O$ aço estudado possui a seguinte composição química $0,26 \% \mathrm{C}-1,13 \% \mathrm{Mn}-0,92 \% \mathrm{Si}-0,72 \% \mathrm{Cr}$ $0,29 \% \mathrm{Mo}-0,18 \% \mathrm{Ni}-0,17 \% \mathrm{Cu}$. Conduziu-se os tratamentos térmicos na sequência apresentada: recozimento subcrítico a $700^{\circ} \mathrm{C}$, têmpera em óleo (temperatura de austenitização $940^{\circ} \mathrm{C}$ ) e tratamento isotérmico de transformação bainítica (temperatura de austenitização de $820,860,900$ e $940^{\circ} \mathrm{C}$ ) ou recozimento subcrítico a $700^{\circ} \mathrm{C}$ seguido de têmpera/revenimento $\left(940^{\circ} \mathrm{C}\right.$ e resfriamento em água $/ 250^{\circ} \mathrm{C}$ por 2 horas). Microscopia Eletrônica de Varredura (MEV) foi empregada para se avaliar a microestrutura do aço. Dureza Rockwell C foi utilizada com intuito de comparar a dureza das diversas microestruturas obtidas. Constatou-se que com a diminuição da temperatura de austenitização houve decréscimo do valor de dureza; e as amostras temperadas e revenidas demonstraram dureza média maior que as amostras que passaram por tratamento isotérmico de bainitização. A microestrutura multiconstituída foi obtida.

Palavras-chave: Austenita retida; Microestrutura multiconstituída; Têmpera e revenimento; Desgaste abrasivo.

\section{ACHIVEMENT OF MULTIPHASE MICROSTRUCTURE IN A LOW-ALLOY STEEL BY BAINITIC TRANSFORMATION ISOTHERMAL TREATMENT}

\section{Abstract}

Wear resistant steels are widely employed on structural components that require properties as tensile strength, toughness and abrasive wear resistance. This work was carried to develop materials to minimize the effects caused by abrasive wear. It aims to: get multiphase microstructure (ferrite, bainite, martensite and retained austenite) by heat treatment; and compare it to tempered martensitic microstructure. The steel has the following chemical composition $0.26 \mathrm{C}-1.13 \mathrm{Mn}-0.92 \mathrm{Si}-0.72 \mathrm{Cr}-0.29 \mathrm{Mo}-0.18 \mathrm{Ni}-0.17 \mathrm{Cu}(\% \mathrm{w})$. Heat treatments were executed in the following sequence: subcritical annealing at $700^{\circ} \mathrm{C}$, quenching in oil $\left(940^{\circ} \mathrm{C}\right)$ and isothermal treatment bainitic transformation (austenitizing temperature of 820 , 860,900 and $940^{\circ} \mathrm{C}$ ) or subcritical annealing at $700^{\circ} \mathrm{C}$ followed by quenching / tempering $\left(940^{\circ} \mathrm{C}\right.$ and cooling in water $/ 250^{\circ} \mathrm{C}$ for 2 hours). Scanning Electron Microscopy (SEM) was used to evaluate the microstructure of the steel. Rockwell $C$ hardness was used in order to compare the hardness of different microstructures obtained. It was found that with decreasing of the intercritical temperature the hardness value declined; and quenched and tempered samples showed an average hardness similar to those found for samples heated isothermally with intercritical temperature of $940^{\circ} \mathrm{C}$ hardness average values. The employed heat treatment enabled multiphase microstructure in the material.

Keywords: Retained austenite; Multiphase microstructure; Quenching and tempering; Abrasive wear.

1 Engenheiro de Materiais, mestrando, Departamento de Engenharia de Materiais, CEFET-MG, Belo Horizonte, Minas Gerais, Brasil.

2 Físico, Doutor Eng. Metalúrgica, Docente, Depto. de Ciências, CEFET-MG, Belo Horizonte, MG, Brasil.

3 Engenheira Metalurgista, Doutora Engenharia Metalúrgica, Docente, Depto. Eng. de Materiais, CEFETMG, Belo Horizonte, MG, Brasil. 


\section{INTRODUÇÃO}

Desgaste abrasivo é um mecanismo de desgaste muito comum observado quando uma superfície dura e rugosa de um objeto desliza sobre outra mais macia e plana. Este mecanismo é um problema dispendioso para vários setores da indústria: automotiva, transporte, mineração e agricultura. Resistência à abrasão não é uma propriedade intrínseca de materiais, mas a resposta de um sistema tribológico que depende das condições de ensaio ou aplicação [1].

Com intuito de reduzir custos e melhorar a eficiência de transportes, aços baixa liga de alta resistência (HSLA) são amplamente empregados na fabricação atual de carros devido à sua excelente combinação entre resistência mecânica e tenacidade, além de boa soldabilidade [2].

Uma boa combinação de alta resistência mecânica, excelente ductilidade e tenacidade pode ser obtida pela contribuição de uma microestrutura multiconstituída e presença de austenita retida. Em um aço multiconstituído comum, a bainita e a martensita, normalmente, contribuem para a resistência mecânica, já a ferrita modifica a taxa de encruamento durante o estágio inicial do escoamento, desta forma a ductilidade é melhorada. As contribuições de diversas fases/constituintes resultam em propriedades mecânicas superiores [3].

Em aços TRIP (transformation induced-plasticity) tradicionais, a microestrutura multiconstituída é obtida por recozimento na região de dual-phase (austenita e ferrita), enquanto a austenita retida é conseguida pelo processo de austêmpera de um estágio; tratamento isotérmico na região de transformação bainítica [3].

Resistência à abrasão de materiais metálicos depende da dureza, tamanho, forma e quantidade de componentes microestruturais duros e suas distribuições na matriz do material. $\mathrm{O}$ aumento da dureza destas fases e suas quantidades na microestrutura aumentam a resistência à abrasão do material. Porém, a participação de carbonetos não pode ser considerada separadamente do material como um todo. Por exemplo, em microestruturas com base em perlita/carbonetos a dureza e a resistência à abrasão aumentam com o crescimento do volume de carbonetos até $35 \%$. Entretanto, em microestruturas baseadas em ferrita/carbonetos o crescimento é eficiente apenas até, aproximadamente, $6 \%$. Além da distribuição dos carbonetos, deve-se considerar tamanho desses e as fases presentes. A resistência à abrasão de aços aumenta com a mudança do tipo de carboneto, por exemplo, quando mudase de um carboneto do tipo $\mathrm{M}_{3} \mathrm{C}$ a um tipo mais complexo, $\mathrm{M}_{7} \mathrm{C}_{3}$, a resistência a abrasão aumenta [4].

Baseando-se na importância da microestrutura em propriedades mecânicas e tribológicas de aços, este trabalho objetiva fornecer microestrutura multiconstituída para um aço baixa-liga; avaliar esta microestrutura a partir de microscopia eletrônica de varredura (MEV) e dureza; e comparar a microestrutura multiconstituída com a martensítica revenida.

\section{MATERIAIS E MÉTODOS}

O aço baixa-liga analisado, recebido em barras, possui a seguinte composição química: 0,26\%C-1,13\%Mn-0,92\%Si-0,72\%Cr-0,29\%Mo-0,18\%Ni-0,17\%Cu.

O material possui dureza de $470 \mathrm{HV}$, o que dificulta a usinagem, portanto, antes dos tratamentos térmicos aplicou-se recozimento subcrítico para diminuir a dureza do aço. As barras de aço foram submetidas a $700^{\circ} \mathrm{C}$ por 10 horas e o resfriamento se deu no próprio forno desligado [5]. Os tratamentos isotérmicos de transformação 
bainítica foram conduzidos da seguinte maneira [5,6]: têmpera em óleo $\left(940^{\circ} \mathrm{C}\right.$ por 10 minutos) para refino de grão e, em sequência, as amostras foram aquecidas à região de austenita $\left(820^{\circ} \mathrm{C} / 860^{\circ} \mathrm{C} / 900^{\circ} \mathrm{C} / 940^{\circ} \mathrm{C}\right.$ por 10 minutos) e resfriadas rapidamente à região bainítica em banho de chumbo $\left(400^{\circ} \mathrm{C}\right.$ por 5 minutos), então foram resfriadas bruscamente em água. As amostras temperadas e revenidas foram aquecidas até a temperatura de $940^{\circ} \mathrm{C}$ por 10 minutos e resfriadas em óleo a temperatura ambiente; logo depois, submeteu-se as amostras ao tratamento de revenimento a $250^{\circ} \mathrm{C}$ por 2 horas e resfriamento lento dentro do forno.

A partir de microscopia de varredura (MEV) obteve-se as micrografias do aço após os tratamentos térmicos. Empregou-se o reagente químico nital 3\% para o ataque químico das superfícies das amostras.

Os valores de dureza média do material em cada condição, descritas anteriormente, foram avaliados por escala de dureza Rockwell $\mathrm{C}$ que foi convertida em Vickers.

\section{RESULTADOS E DISCUSSÃO}

Assim como em $[3,6]$, com intuito de obter microestrutura refinada, pré-tempera foi aplicada antes da austêmpera interrompida (tratamento istotérmico de bainitização). As micrografias obtidas estão representadas nas figuras 1, 2, 3, 4 e 5 . Nas figuras de 1 a 4, observa-se uma microestrutura multiconstituída que apresenta ferrita $(F)$, bainita (B) e martensita/austenita retida (MA). A figura 5 indica a microestrutura do material temperado e revenido. De acordo com $[6 ; 7 ; 8]$, as microestruturas multiconstituídas observadas em MEV podem se apresentar do seguinte modo: a ferrita como regiões mais profundas (mais escuras), a bainita como lamelas, e a martensita/austenita retida como blocos (regiões mais elevadas). Estas regiões podem ser identificadas nas imagens a seguir.

$\mathrm{Na}$ figura 1, observa-se que há bastante ferrita bainítica e pouca equiaxial; e a martensita e austenita retida (MA) apresentam morfologia de pequenos blocos. $\mathrm{Na}$ figura 2, também percebe-se poucos grãos de ferrita equiaxial e muita ferrita bainítica. Porém, os pacotes de bainita se apresentaram menores e mais definidos, em relação à figura 1. Já os blocos de MA se mostraram maiores que a imagem anterior. A figura 3 indica que os pacotes de bainita começam a se apresentar mais definido que nas micrografias anteriores e há menos blocos de MA. A microestrutura do aço, após tratamento térmico de austêmpera a partir da temperatura intercrítica de $940^{\circ} \mathrm{C}$, mostrada na figura 4 apresenta pacotes de bainita maiores e mais definidos. A ferrita equiaxial formada é desprezível, observa-se, praticamente, ferrita bainítica, observa-se, também, ausência de blocos de MA. 


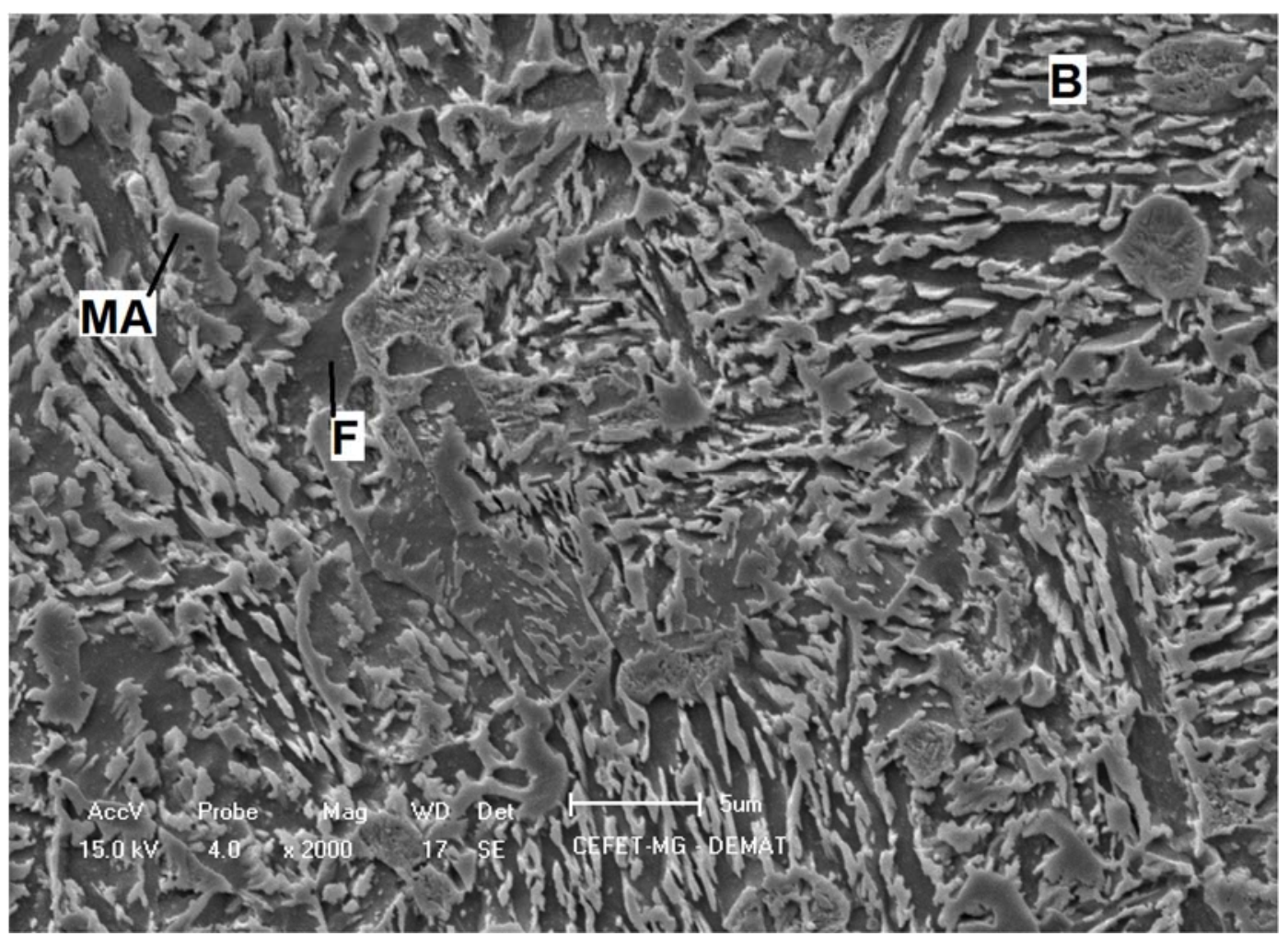

Figura 1 - MEV de amostra submetida à transformação bainítica (temperatura de austenitização de $\left.820^{\circ} \mathrm{C}\right)$.

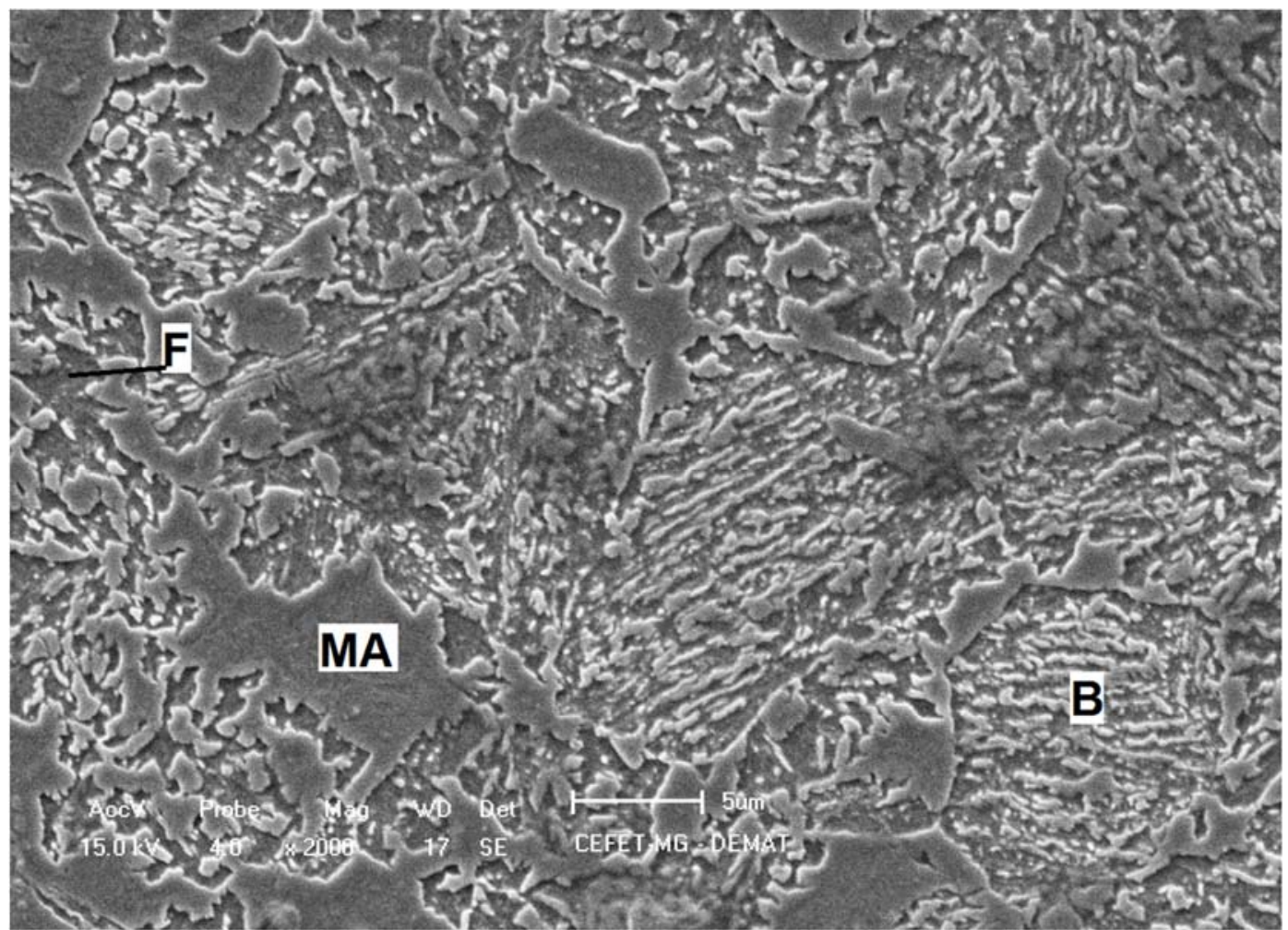

Figura 2 - MEV de amostra submetida à transformação bainítica (temperatura de austenitização de $\left.860^{\circ} \mathrm{C}\right)$. 

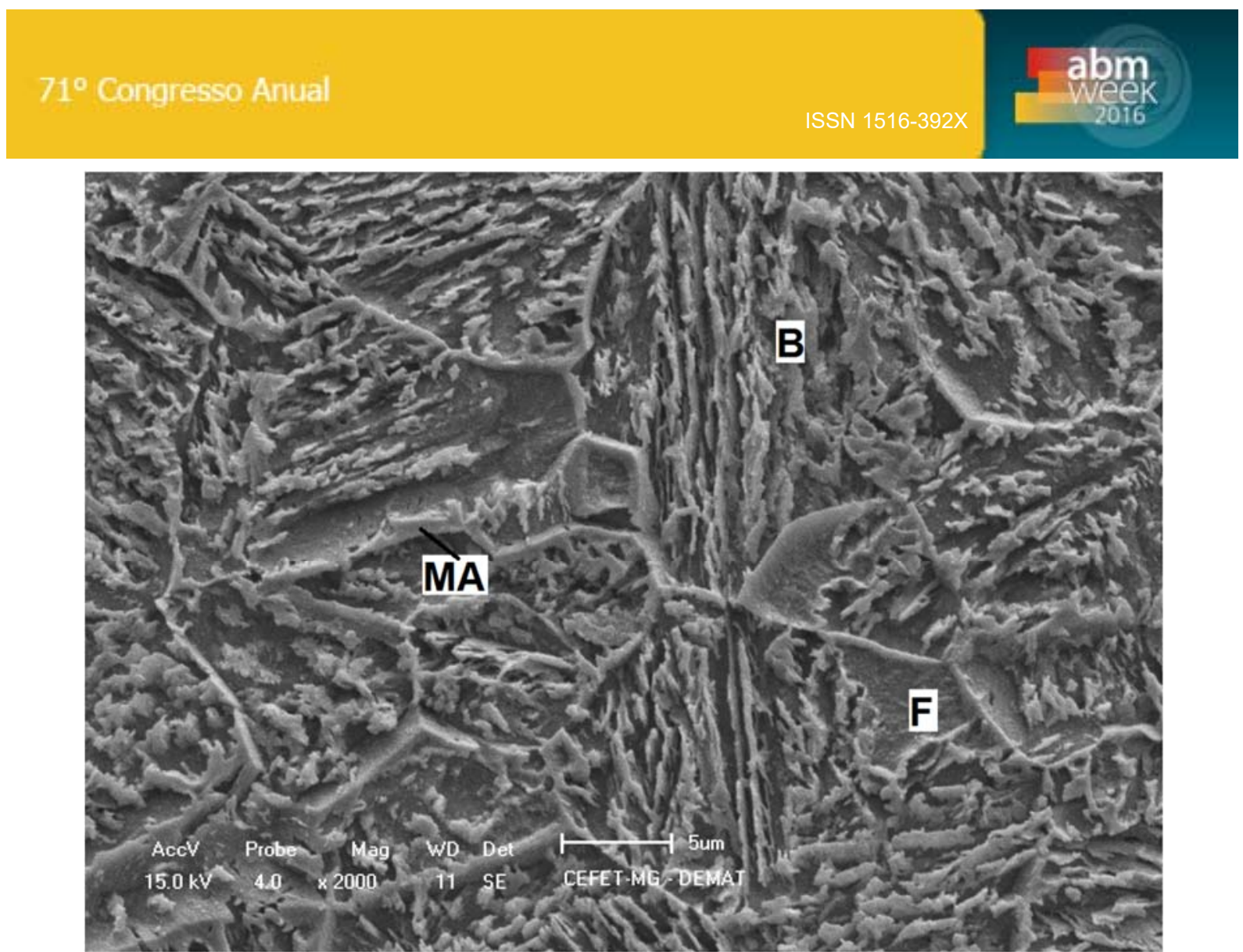

Figura 3 - MEV de amostra submetida à transformação bainítica (temperatura de austenitização de $\left.900^{\circ} \mathrm{C}\right)$.

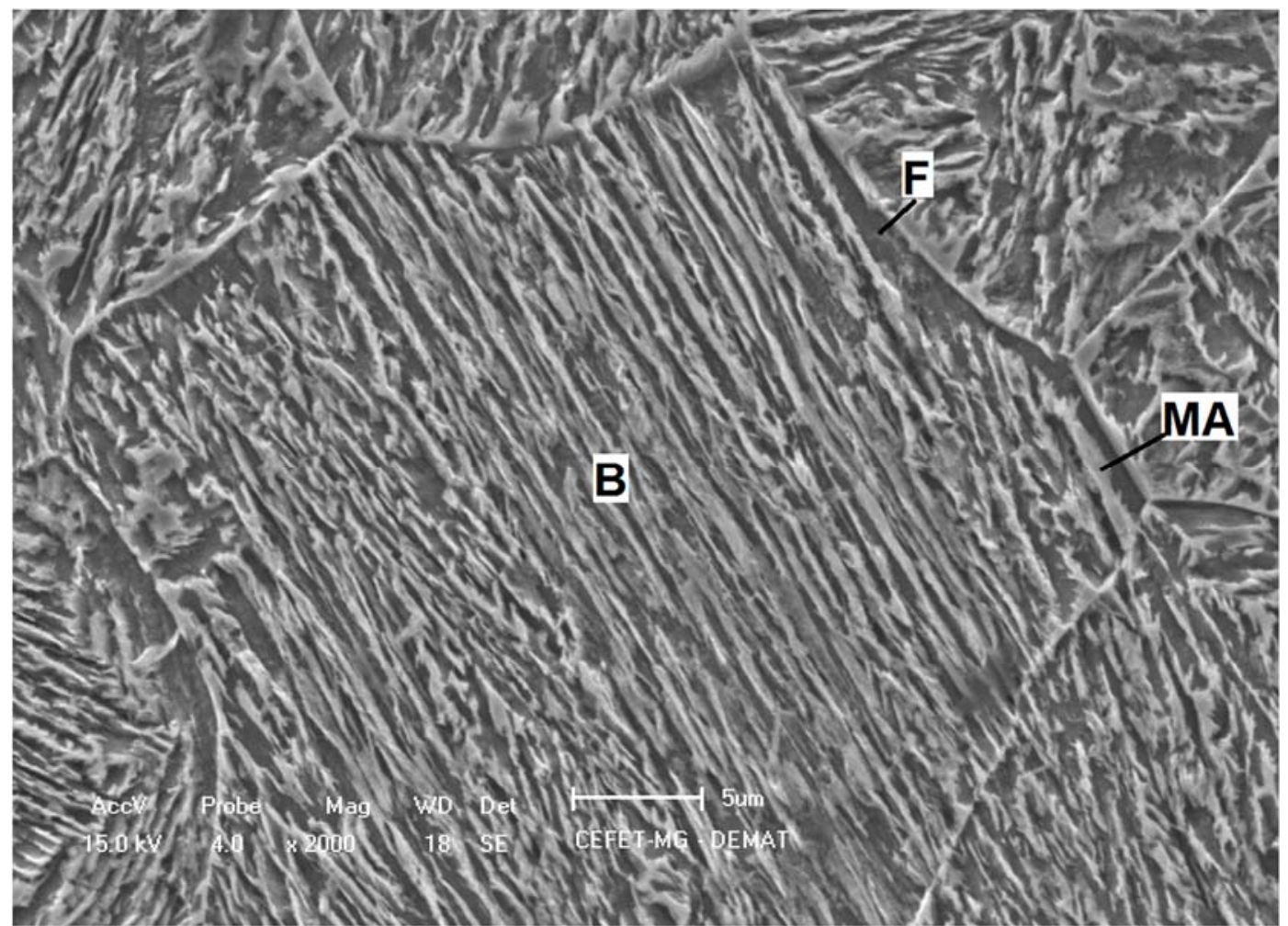

Figura 4 - MEV de amostra submetida à transformação bainítica (temperatura de austenitização de $\left.940^{\circ} \mathrm{C}\right)$. 

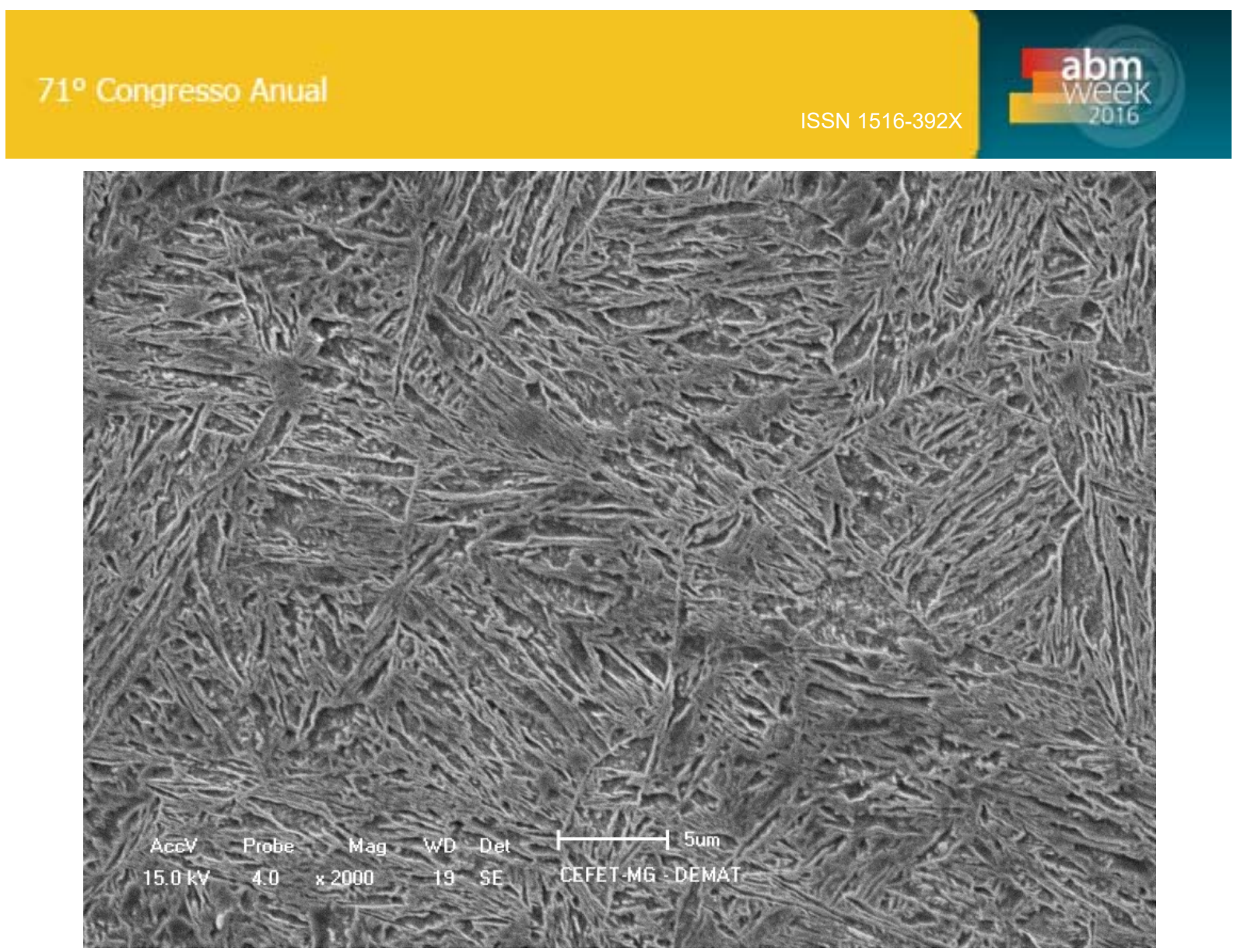

Figura 5 - MEV de amostra submetida à têmpera e revenimento.

Neste trabalho, variando-se a temperatura intercrítica, buscou-se avaliar a quantidade de austenita na microestrutura. A presença de austenita retida na microestrutura está diretamente relacionada à formação de bainita. Assim que a bainita se forma, a concentração de carbono na austenita aumenta, o que eleva a estabilidade desta fase, possibilitando a formação de austenita retida quando o aço for temperado em temperatura ambiente (ar, água ou óleo) [6]. A bainita é formada como constituinte principal em resfriamento rápido diretamente de temperaturas intercríticas mais altas. Entretanto, ferrita é, principalmente, formada sob temperaturas intercríticas mais baixas. Quando a bainita é o constituinte dominante, a estabilidade da austenita retida é, inevitavelmente, menor uma vez que possui menor teor de carbono [9].

A partir da figura 6 , observam-se os valores médios de dureza apresentados pelo aço nas condições propostas. 


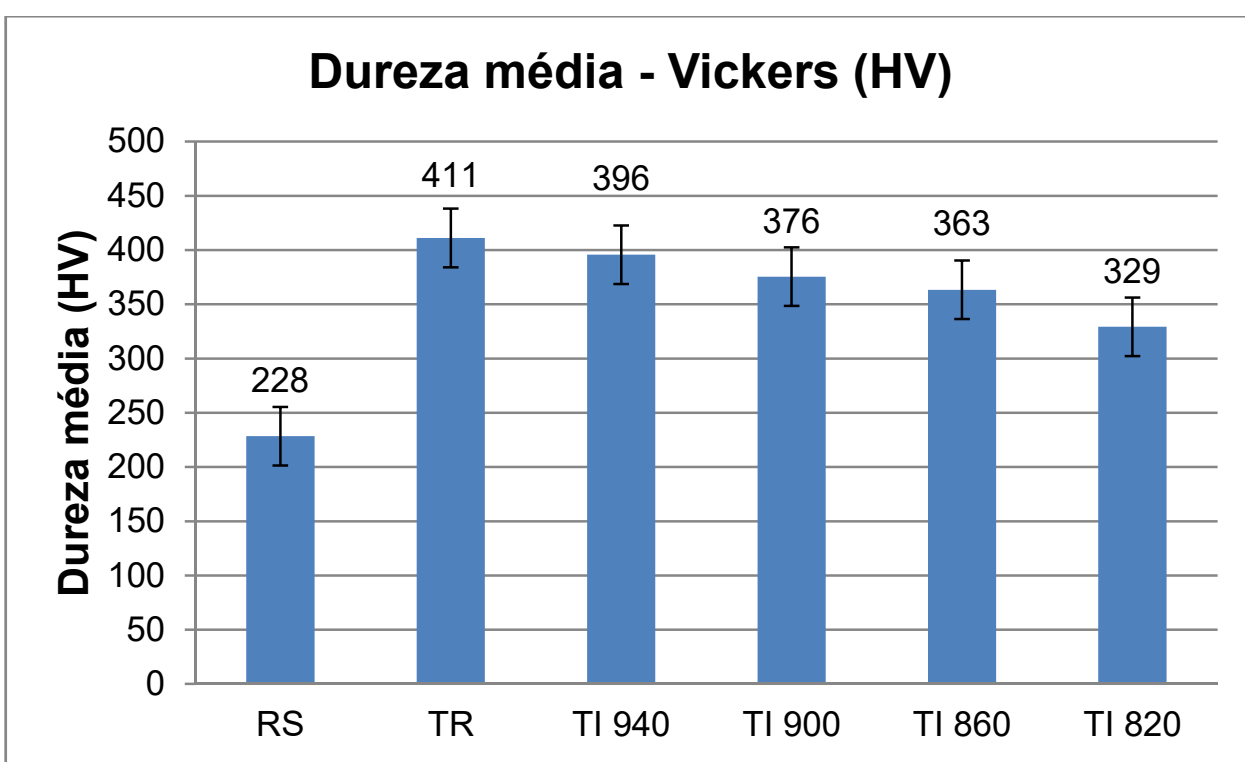

Figura 6 - Valores de dureza média - Escala Rockwell C convertida em Vickers. RS - Recozimento subcrítico; TR-Têmpera e revenimento; TI 940 - Tratamento isotérmico com temperatura intercrítica de $940^{\circ} \mathrm{C}$; $\mathrm{TI} 900$ - de $900^{\circ} \mathrm{C}$; $\mathrm{TI} 860$ - de $860^{\circ} \mathrm{C}$; $\mathrm{TI} 820$ - de $820^{\circ} \mathrm{C}$.

Constatou-se que o aço temperado e revenido apresentou dureza média maior que o tratado isotermicamente independente da temperatura de austenitização. Devido sua microestrutura ser completamente martensítica revenida, como vista na figura 5. Os valores de dureza diminuíram proporcionalmente ao decréscimo da temperatura intercrítica, condizente com as microestruturas das figuras 1, 2 e 3, obtidas por meio de resfriamento rápido a partir de temperaturas intercríticas, contendo ferrita $(F)$, bainita (B) e martensita/austenita retida (MA). A figura 4 já apresenta uma microestrutura predominantemente bainítica, portanto, com maior dureza que as anteriores. A presença da ferrita proporciona uma diminuição da dureza e um aumento da ductilidade. Além do mais, a ferrita aceita facilmente a expansão volumétrica da austenita retida na transformação induzida por deformação (TRIP) [9].

\section{CONCLUSÃO}

Conseguiu-se garantir ao aço uma microestrutura multiconstituída por ferrita, bainita, martensita e austenita retida. Temperatura intercrítica de $940^{\circ} \mathrm{C}$ garantiu ao material microestrutura, aproximadamente, bainítica, propiciando alta dureza do aço. As demais temperaturas (mais baixas), propiciou microestrutura multiconstituída, em que constatou-se presença distintas de pacotes de bainita e morfologia da microfase MA (martenista/austenita retida). A dureza média do aço temperado e revenido mostrou-se maior que as demais condições. Para as amostras submetidas ao tratamento isotérmico de bainitização, à medida que a temperatura de austenitização aumentou, os valores médios da dureza se elevaram.

\section{Agradecimentos}

Ao Centro Federal de Educação Tecnológica de Minas Gerais (CEFET/MG) pelo apoio (bolsa) durante o programa de Mestrado em Engenharia de Materiais (20142016). 


\section{REFERÊNCIAS}

1. Xu X, Xu W, Ederveen FH, Zwaag SVD. Design of low hardness abrasion resistant steels. Wear. 2013; 301: 89-93.

2. Yan W, Zhu L, Sha W, Shan YY, Yang K. Change of tensile behavior of a high-strength low-alloy steel with tempering temperature. Materials Science \& Engineering A. 2009; 512: 369-374.

3. Xie ZJ, Ren YQ, Zhow WH, Yang JR, Shang CJ, Misra RDK. Stability of retained austenite in multi-phase microstructure during austempering and its effect on the ductility of a low carbon steel. Materials Science \& Engineering A. 2014; 603: 69-75.

4. Suchánek J, Kuklív V, Zdravecká E. Influence of heat and thermochemical treatment on abrasion resistance of structural and tool steels. Wear. 2009; 267: 2100-2108.

5. Dos Santos FLF, Vieira AG, Corrêa ECS, Pinheiro IP. Avaliação mecânica e estrutural de um aço resistente ao desgaste. In: Congresso Brasileiro de Engenharia e Ciência dos Materiais. Anais do $19^{\circ}$ Congresso Brasileiro de Engenharia e Ciência dos Materiais; 2010; Campos do Jordão, Brasil. 2010. p. 5381-5388.

6. Chiang J, Lawrence B, Boyd JD, Pilkey AK. Effect of microstructure on retained austenite stability and work hardening of TRIP steels. Materials Science \& Engineering A. 2011; 528: 4516-4521.

7. Bouquerel J, Verbeken K, De Cooman BC. Microstructure-based model for the static mechanical behavior of multiphase steels. Acta Materialia. 2006; 54: 1443-1456.

8. Hosseini SMK, Hanzaki AZ, Yue S. Effect of austenite deformation in nonrecrystallization region on microstructure development in low-silicon content TRIPassisted steels, Materials Science \& Engineering. 2014; 618: 63-70.

9. Matsumura O, Sakuma Y, Takechi H. Enhancement of elongation by retained austenite in intercritical annealed 0.4C-1.5Si-0.8Mn steel. Transactions ISIJ. 1987; 27: 570-579. 